\title{
Bacteriophage therapy: practicability and clinical need meet in the multidrug-resistance era
}
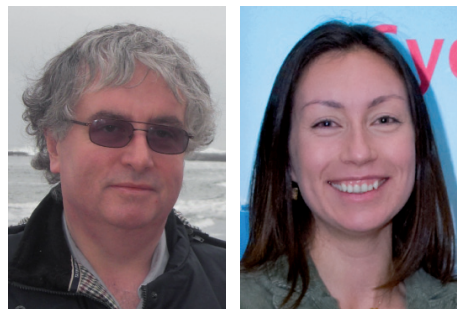

\author{
“....with advances in molecular \\ techniques and ... knowledge about \\ phage biology, companies now have the \\ upper hand in making the second wave \\ of phage therapy a successful one."
}

David R Harper*1 \& Sandra Morales²

'AmpliPhi Biosciences Corp., Colworth Science Park, Sharnbrook, Bedfordshire, MK44 1LQ, UK

2Special Phage Services, 7/27 Dale Street, Brookvale, NSW 2100, Australia

*Author for correspondence: Tel.: +448456800971 =drh@ampliphibio.com

It is now an accepted truth that while antibiotic resistance is rising, the pipeline of new antibiotics is in many cases almost empty [1]. This is particularly true for the multiresistant Gramnegative bacteria such as Pseudomonas aeruginosa and Acinetobacter baumannii [2]. However, it would be unwise to think that only conventional small-molecule antibiotics can help to stem the tide of resistance. A range of other approaches exists, and bacteriophage therapy is one of these.

66. .. it is impossible to consider the possible uses of bacteriophage therapy without awareness of its history, which is both long and conflicted."

Bacteriophages (often known simply as phages) are naturally occurring viruses that infect bacteria. As such, they are unaffected by antibiotic resistance and (unlike many antibiotics) are able to target bacteria within biofilms [3]. They can either coexist with their host by inserting themselves into the bacterial genome (lysogenic bacteriophages) or destroy them (lytic bacteriophages; the type most suited to therapeutic use). Lytic bacteriophages replicate inside their hosts then release many new bacteriophages that are able to infect more bacteria. 'Bacteriophage therapy' is the term used for the practical application of these very powerful lytic viruses for the treatment of infection. The concept may appear novel, but the technique has been used for over 90 years, and its use continues to the present day in countries such as the Republic of Georgia, where it is part of standard healthcare protocols [101]. Thus, it is impossible to consider the possible uses of bacteriophage therapy without awareness of its history, which is both long and conflicted.

Bacteriophages were first identified independently in 1915 and 1917 [4]. Success in treating both animal and human disease was reported shortly afterwards and multiple studies followed. A total of 150 papers had been published by 1925 [5] and many thousands of people were treated. However, with so little known about the basic biology of bacteriophages that even their existence was in dispute, the commercial development and application of appropriate treatments were often misdirected, resulting in variable levels of success. This led to confusion, disagreement and an increasingly bitter debate between supporters and opponents of phages that escalated following the publication of a critical review by the American Medical Association [6]. This report concluded, on the balance of evidence, that bacteriophages did not exist and the therapeutic effects observed could be explained by the action of enzymes. Even after the publication of the first electron micrographs of phages in 1940, doubt remained. The final blow came with a second report by Krueger and Scribner in 1941, which stated that "Phage is a protein of high molecular weight" [7]. This early uncertainty was to cast a long shadow over the field as a whole.

At the same time, the first antibiotics were starting to appear. These new agents showed broad activity and thus their clinical applicability was more attractive than that of bacteriophages [8]. While the clinical use of bacteriophages continued for some time, chemical antibiotics were seen as the mainstream answer

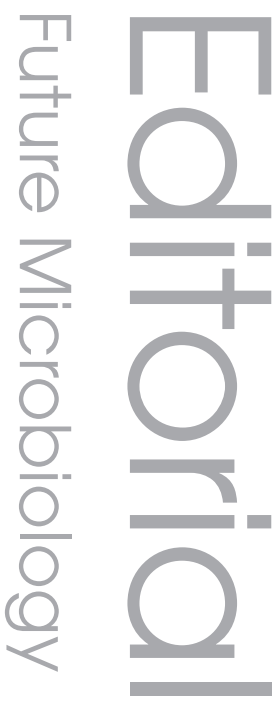

\section{Keywords}

- antibiotic resistance

- bacteriophage

- bacteriophage therapy

- clinical trial

Future $\because$ Medicine part of 
to bacterial disease. Large-scale use of bacteriophage therapeutics was to survive only at centers in eastern Europe [9], although small-scale use did continue for some time in the west, notably in France and Switzerland.

Meanwhile, bacteriophages were proving to be very useful tools in the emerging field of molecular biology. Along with the many insights that such work provided came hugely increased understanding of the bacteriophages themselves. This meant that, in the 1980s, when a small group in the UK decided to look again at bacteriophage therapy in mice and in calves, they could do so based on a sound understanding of bacteriophage biology. The outcomes of that work are best summarized by the title of one of their papers: 'Successful treatment of experimental Escherichia coli infections in mice using phage: its general superiority over antibiotics' $[10]$. That their work did not receive much attention reflects both their choice of target and the still extant perception that antibiotics were working. This perception was not to last much longer.

"It was in the context of this emerging
crisis of antibiotic resistance that
attention once again turned to the
possibilities of using bacteriophages."

Nowadays, it seems odd to look back on the days when there was such confidence that antibiotics had finally defeated bacterial disease. William Stewart, the US Surgeon General, denied that he ever said in 1969, "It's time to close the book on infectious diseases, declare the war against pestilence won," but this certainly reflected the mood of the time, when there was a belief that medicine should move on to other challenges. By the 1990s, it was becoming clear that the war against pestilence was anything but over. Antibiotic-resistant 'superbugs', spearheaded (at least initially) by methicillinresistant Staphylococcus aureus, were becoming increasingly common, and speculation about a 'postantibiotic era' had already begun. It was in the context of this emerging crisis of antibiotic resistance that attention once again turned to the possibilities of using bacteriophages.

Given that the therapeutic use of bacteriophages had continued in eastern Europe, several groups sought to bring these methods and approaches back to the west. However, their attempts were hampered by a combination of factors including political upheaval, language differences and the realization that the protocols in use would be incompatible with western regulatory agencies such as the US FDA, the EMA and the Therapeutic Goods Administration (TGA). As a result, a small number of workers in the west elected to start from scratch. Multiple publications appeared suggesting that bacteriophages had potential as anti-infective agents and demonstrating their efficacy in a variety of animal models [11,12]. In the face of a looming antibiotic resistance crisis, these results sparked new interest in bacteriophage therapy.

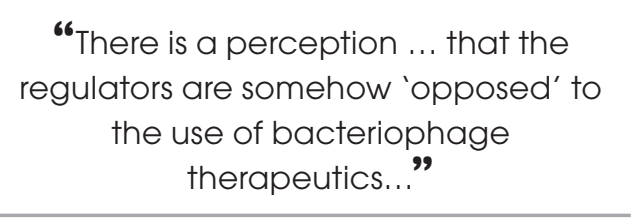

The first modern clinical trial of a bacteriophage therapeutic was a Phase I safety trial carried out by the company Exponential Biotherapies Inc. in London in 1999, targeting vancomycin-resistant Enterococcus. The results of the trial were never formally reported, but this work was followed by other Phase I trials [13,14], including one carried out in Switzerland by the food multinational, Nestlé [15]. These were followed by long overdue controlled trials in patients with the target disease - Phase II clinical trials - where the effect of such treatments on bacterial infection could be evaluated. The first such trial was carried out in 2006-2007 at a specialist ear hospital in London, UK. Patients with chronic ear disease caused by $P$. aeruginosa were treated with a single, 2.4-ng dose of a mixture of six bacteriophages [16]. The results showed that within 6 weeks, $92 \%$ patients had improved, and $25 \%$ had resolved their infection. These were patients who had been ill for up to 40 years and had been treated with many different antibiotics. These results, published in 2009, provided the first evidence from a modern clinical trial that bacteriophages could be effective in controlling bacterial disease in humans. The field continues to develop, and following on from the Swiss study noted above [15], another Phase II trial is now under way in Bangladesh.

For sceptical westerners, both researchers and clinicians, here at last were clinical trial data, carried out under strict regulatory guidelines, which indicated that bacteriophage therapy can work. Alongside this process, bacteriophage products were being approved in the food sector, at both the start and end of the food chain - from animal feeds and sprays to treatments for ready-to-eat foods [17].

Given that there is an urgent need for novel approaches to control bacterial disease, 
what is needed to take bacteriophage therapy into mainstream medicine?

The basic requirement is for bacteriophage products to progress through standard regulatory pathways. Although the lack of a specific path for bacteriophage therapeutics has been noted [18], there exist substantial precedents in the use of live vaccines and of biological therapies in both Europe and the USA. There is a perception, particularly among some scientists in the field, that the regulators are somehow 'opposed' to the use of bacteriophage therapeutics and there has been pressure for modification to and even relaxation of the regulatory process [18]. This seems unlikely to succeed at this stage. As the results of Phase III trials confirm their safety and efficacy and bacteriophage-based products enter the market, it may make sense for the regulators to develop more specific regulatory pathways. It is harder to justify a case for something that is still only in early-stage trials.
Fortunately, with advances in molecular techniques and using extensive current knowledge about phage biology, companies now have the upper hand in making the second wave of phage therapy a successful one. This process is under way, and many necessary steps have already been taken. So, despite a controversial beginning, and almost 100 years on, d'Herelle's phage therapy may at last be about to fulfill its potential.

\section{Financial \& competing interests disclosure \\ DR Harper is an officer of and shareholder in AmpliPhi Biosciences Corp. and a director and employee of Biocontrol Ltd. S Morales is an employee of Special Phage Services. The authors have no other relevant affiliations or financial involvement with any organi- zation or entity with a financial interest in or financial conflict with the subject matter or materials discussed in the manuscript apart from those disclosed. \\ No writing assistance was utilized in the production of this manuscript.}

\section{References}

Papers of special note have been highlighted as:

- of interest

-. of considerable interest

1. Cooper MA, Shlaes D. Fix the antibiotics pipeline. Nature 472, 32 (2011).

2. Theuretzbacher U. Accelerating resistance, inadequate antibacterial drug pipelines and international responses. Int. J. Antimicrob. Agents 39(4), 295-299 (2012).

3. Donlan RM. Preventing biofilms of clinically relevant organisms using bacteriophage. Trends Microbiol. 17(2), 66-72 (2009).

4. Duckworth DH. Who discovered bacteriophage? Bacteriol. Rev. 40, 793-802 (1976).

5. Summers WC. Felix d'Herelle and the Origins of Molecular Biology. Yale University Press, CT, USA (1999).

6. Eaton M, Bayne-Jones S. Review of the principles and results of the use of bacteriophage in the treatment of infections. JAMA 103(23), 1769-1776 (1934).

7. Krueger AP, Scribner EJ. The bacteriophage: its nature and its therapeutic use. JAMA 116, 2160-2167 (1941).

8. Harper DR, Anderson J, Enright MC. Phage therapy: delivering on the promise. Therapeutic Delivery 2(7), 935-947 (2011).

- Provides a fairly current review of this area.
9. Sulakvelidze A, Alavidze Z, Morris JG. Bacteriophage therapy. Antimicrob. Agents Chemother. 45, 649-669 (2001).

- Provides a detailed review of eastern European work in this area.

10. Smith HW, Huggins MB. Successful treatment of experimental Escherichia coli infections in mice using phage: its general superiority over antibiotics. J. Gen. Microbiol. 128, 307-318 (1982).

- First modern study of the efficacy of therapeutic bacteriophages, and underpinned the revival of interest in this area.

11. Soothill JS. Treatment of experimental infections of mice with bacteriophages. J. Med. Microbiol. 37, 258-261 (1992).

12. Merrill CR, Biswas B, Carlton R et al. Long-circulating bacteriophage as antibacterial agents. Proc. Natl Acad. Sci. USA 93, 3188-3192 (1996).

13. Rhoads DD, Wolcott RD, Kuskowski MA, Wolcott BM, Ward LS, Sulakvelidze A. Bacteriophage therapy of venous leg ulcers in humans: results of a Phase I safety trial. J. Wound Care 18, 237-243 (2009).

14. Merabishvili M, Pirnay JP, Verbeken G et al. Quality-controlled small-scale production of a well-defined bacteriophage cocktail for use in human clinical trials. PLoS One 4(3), e4944 (2009).
15. Bruttin A, Brussow H. Human volunteers receiving Escherichia coli phage T4 orally: a safety test of phage therapy. Antimicrob. Agents Chemother. 49, 2874-2878 (2005).

- First publication of a modern safety trial in humans.

16. Wright $\mathrm{A}$, Hawkins $\mathrm{CH}$, Anggård EE, Harper DR. A controlled clinical trial of a therapeutic bacteriophage preparation in chronic otitis due to antibiotic-resistant Pseudomonas aeruginosa; a preliminary report of efficacy. Clin. Otolaryngol. 34, 349-357 (2009).

- First demonstration of the efficacy of a bacteriophage therapeutic in a modern clinical trial.

17. Monk AB, Rees CD, Barrow P, Hagens S, Harper DR. Bacteriophage applications: where are we now? Lett. Appl. Microbiol. 51(4), 363-369 (2010).

18. Verbeken G, Pirnay JP, De Vos D et al. Optimizing the European regulatory framework for sustainable bacteriophage therapy in human medicine. Arch. Immunol. Ther. Exp. (Warsz.) 60(3), 161-172 (2012).

\section{Website}

101. Harper DR, Kutter E. Bacteriophage: therapeutic uses. In: The Encyclopedia of Life Sciences. John Wiley \& Sons, UK (2008). www.els.net/WileyCDA/ElsArticle/ refId-a0020000.html 